\title{
Medicamentos órfãos - doenças raras e a judicialização da saúde
} Orphan drugs - rare diseases and health judicialization

\author{
Anselmo Gomes de OLIVEIRA; \\ Dâmaris SILVEIRA \\ Editores de Infarma - Ciências Farmacêuticas
}

A Justiça tem se tornado um dos caminhos utilizados mais comuns para resolver problemas de acesso a medicamentos; algumas vezes em fase de estudo experimental e sem registro no país e, em outras, medicamentos para tratamento de doenças específicas.

No rol dos medicamentos mais polêmicos, envolvidos em processos judiciais, estão aqueles impostos ao Sistema Único de Saúde (SUS), medicamentos de alto custo, medicamentos off label e medicamentos com eficácia questionável, principalmente para tratamento de doenças crônicas, como câncer, hepatites, diabetes, doenças raras, entre outras.

Contudo, as intervenções do judiciário na área dos medicamentos não têm sido vistas pelos gestores da área da saúde como um caminho saudável na solução dos problemas, mas sim como um procedimento inadequado e disseminador de medicamentos muitas vezes não testados e cujas observações de eficácia não são de domínio de quem o prescreveu.

O número crescente de doenças raras é um importante problema de saúde pública, não só em países em desenvolvimento como o Brasil, devido, em grande parte, à falta de incentivo dos governos para os fabricantes locais de medicamentos considerados "órfãos". A maioria das indústrias farmacêuticas é composta de empresas multinacionais e seus interesses particulares muitas vezes são divergentes dos interesses sociais dos países nos quais elas concentram suas atividades. Adicionalmente, não há, por parte dos governos, critérios claros para a inclusão de novos "medicamentos órfãos" nos programas de saúde.

Estima-se que 6-8\% da população mundial sejam portadores de alguma doença rara; e no Brasil, aproximadamente 13 milhões de pessoas são portadores (1). No mundo são conhecidas cerca de 7 mil doenças raras, das quais $80 \%$ são de origem genética, $75 \%$ se manifestam na infância, e cerca de $95 \%$ delas ainda não possuem tratamento disponível (2). Essas parecem ser as principais razões que levam as pessoas a buscarem na justiça o direito ao acesso a muitos medicamentos, às vezes ainda não registrado no país.

$\mathrm{Na}$ Europa, existem cerca de 80 medicamentos com designação "órfão" e com autorização de introdução no mercado (3). No Brasil, 35 tratamentos para doenças raras são cobertos pelo SUS (4) e apenas 45 medicamentos considerados "órfãos" encontram-se registrados para tratamento de aproximadamente 14 doenças raras. É previsível que, nessas condições, a judicialização da saúde pareça ser um caminho compreensível e certamente a previsão de que cerca de $60 \%$ dos recursos totais para a aquisição de medicamentos serão gastos para o atendimento de pacientes com doenças raras (1) não parece fora de propósito .

No Brasil não há uma política direcionada aos medicamentos órfãos, mas, no início de 2014 o Ministério da Saúde estabeleceu, por meio da portaria 199, a Política Nacional para as Pessoas com Doenças Raras (5). Com isso, ainda que não suficiente, houve um avanço significativo na área, pois os medicamentos a serem incorporados devem possuir efetividade clínica comprovada. Assim, a portaria estimula a pesquisa científica e o desenvolvimento científico e tecnológico voltados para a prevenção e tratamento de doenças raras, com ênfase para a produção de novos medicamentos e imunobiológicos. A Portaria 199/2014 também propiciará a adoção de critérios e instrumentos regulatórios específicos para facilitar o registro e a entrada de medicamentos para tratamento de doenças raras no mercado nacional e no SUS.

Evidentemente, a superação destes problemas somente ocorrerá de forma mais incisiva por meio de um marco regulatório brasileiro que considere as características específicas dos medicamentos órfãos e a necessidade de fomentar incentivos para ampliar a disponibilidade de novos medicamentos órfãos no país. $\mathrm{E}$ isso deve ser feito sem comprometer as políticas e o investimento voltados aos outros medicamentos. 


\section{totarma}

\section{REFERÊNCIAS}

1. 1-INTERFARMA. Guia 2015. Associação da Indústria Farmacêutica de Pesquisa http://www.interfarma.org.br/ guia2015/site/guia/index.php?val=47\&titulo $=$ Doen $\%$ C3\%A7as\%20raras

2- PORTUGAL. Programa Nacional para Doenças Raras. 2008. http://ec.europa.eu/health/ph_threats/non_com/ docs/portugal.pdf

3- ORPHANET. Lists of medicinal products for rare diseases in Europe. Orphanet Report Series. October 2015. http://www.orpha.net/orphacom/cahiers/docs/GB/list of_orphan_drugs_in_europe.pdf
4- Arnold RJG; Bighash L; Bryón Nieto A; Araújo GTB; Gay-Molina JG, Augustovski F. The role of globalization in drug development and access to orphan drugs: orphan drug legislation in the US/EU and in Latin America. F1000Research. 2015;4:57. doi:10.12688/f1000research.4268.1.

5- BRASIL. Ministério da Saúde.Politica Nacional de Atenção Integral às Pessoas com Doenças Raras. Portaria 199/2014, 30 de janeiro de 2014 